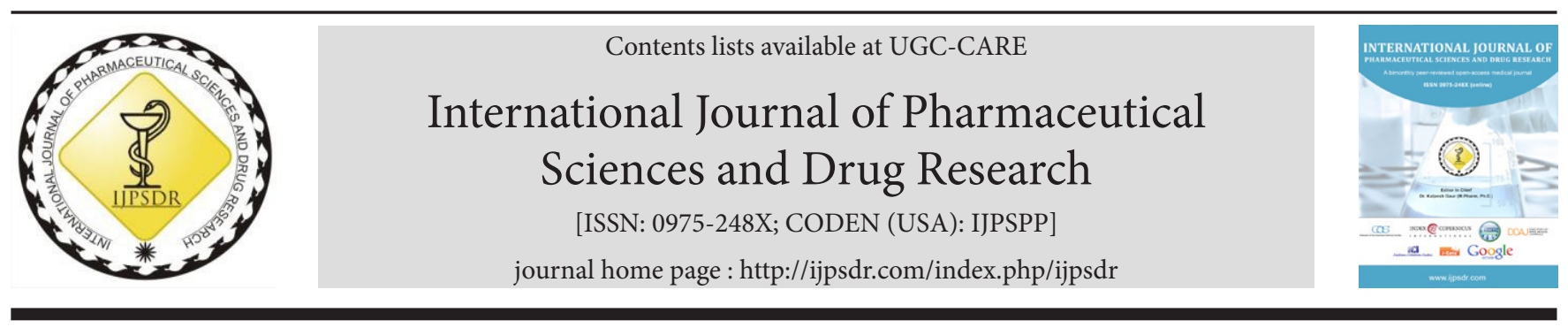

Research Article

\title{
Application of Central Composite Design for Citalopram Hydrogen Bromide Mouth Dissolving Films
}

\author{
Shimmula Rohini Reddy ${ }^{*}$, Bomma Ramesh \\ Department of Pharmacy, Mewar University, Chittorgarh-312901, Rajasthan, India
}

\author{
ART I CLE INFO \\ Article history: \\ Received: 16 April, 2020 \\ Revised: 15 June, 2020 \\ Accepted: 26 June, 2020 \\ Published: 30 July, 2020 \\ Keywords: \\ Antidepressant, \\ Central composite design (CCD), \\ Citalopram $\mathrm{HBr}$, \\ Mouth dissolving films, \\ Solvent casting method. \\ DOI: \\ 10.25004/IJPSDR.2020.120408
}

\begin{abstract}
A B S T R A C T
Citalopram is an antidepressant used for treating major depressive disorder. In the current work, citalopram $\mathrm{HBr}$ is formulated as a mouth-dissolving film with enhanced drug dissolution. The central composite design (CCD), employed to examine the effects of amount of hydroxypropyl methylcellulose (HPMC) E50 (A), amount of maltodextrin (B), and amount of glycerol (C) on response variables tensile strength, disintegration time and cumulative \% drug release. Twenty-seven formulations prepared according to CCD and evaluated for physicochemical parameters and in vitro dissolution studies. Citalopram $\mathrm{HBr}$ mouth dissolving films formulated by employing the solvent-casting method, using HPMC E50, maltodextrin, and glycerol, optimized for the effective dosage of superdisintegrants. The formulation CF21 with a maximum tensile strength of $67.21 \pm 1.31$ grams, least disintegration time of $9 \pm 1.6$ seconds, and highest drug release of $98.41 \pm 1.81 \%$ is chosen optimal formulation with maximum content uniformity and folding endurance. It is evident from the above results that the developed formulation can be an innovative dosage form to improve the drug delivery, quick onset of action, as well as, improve patient compliance in the effective management of depression.
\end{abstract}

\section{INTRODUCTION}

Mouth dissolving films are novel formulation systems that are advantageous over traditional drug delivery systems. They possess the swallowing ease and convenience, which readily disintegrate to dissolve the drug as soon as it comes in contact with saliva fluids. The drug is quickly absorbed and facilitates quicker onset of therapeutic effect by bypassing the metabolism in stomach and gastro intestinal (GI) track. These formulations usually dissolve in oral cavity within 5 seconds to 3 minutes, leaving no residue in the mouth. Mouth dissolving films are employed for drug delivery in children, bedridden, and psychotic patients who otherwise face difficulty in swallowing traditional oral formulations. ${ }^{[1,2]}$

Citalopram is an antidepressant belonging to the selective serotonin reuptake inhibitor (SSRI) class. It is used for treating a major depressive disorder, panic disorders, compulsive disorder, and social phobia. Citalopram undergoes metabolism in the liver by CYP2C19, CYP3A4, and CYP2D6. The half-life of citalopram is about 35 hours, and post intragastric administration, the half-life of citalopram increases to $287 \%$. Even though citalopram was approved by US FDA in 1998, it should be considered as second-line option for adolescent depression. ${ }^{[3]}$

Design of experiments (DoE) is a tool that facilitates concurrent examination of the effect of various independent variables on dependent variables hence, facilitating in optimizing formulation design. The experiment is designed to allow us to estimate interaction and even quadratic effects, and therefore, give us an idea of the (local) shape of the response surface we are investigating. For this reason, they are termed response surface method (RSM) designs. ${ }^{[4]}$

\footnotetext{
"Corresponding Author: Shimmula Rohini Reddy

Address: Department of Pharmacy, Mewar University, Chittorgarh-312901, Rajasthan, India

Email $\bowtie$ : rohinishimmula@gmail.com

Tel.: +91-9885058025

Relevant conflicts of interest/financial disclosures: The authors declare that the research was conducted in the absence of any commercial or financial relationships that could be construed as a potential conflict of interest.

Copyright (C) 2020 Shimmula Rohini Reddy et al. This is an open access article distributed under the terms of the Creative Commons AttributionNonCommercial-ShareAlike 4.0 International License which allows others to remix, tweak, and build upon the work non-commercially, as long as the author is credited and the new creations are licensed under the identical terms.
} 


\section{MATERIALS AND METHODS}

Citalopram $\mathrm{HBr}$ is generously gifted by Hetero Drugs Ltd., Hyderabad, India. All the formulation excipients, HPMC E50, maltodextrin, glycerol, lactose, and aspartame, purchased from Signet Chemicals Corporation Pvt. Ltd., Mumbai, India

\section{Preparation of Citalopram HBr Mouth Dissolving Film}

Mouth dissolving films of citalopram $\mathrm{HBr}$ prepared by the solvent casting method, initially, the polymers soaked in water overnight for attaining uniformity in dispersion. Plasticizer added to these solutions and stirred continuously for 4 to 5 hours, followed by leaving it undisturbed for 1-hour to obtain aqueous layer I (Table 1). Aqueous layer II comprises of citalopram $\mathrm{HBr}$, lactose, and aspartame dissolved in distilled water. The two aqueous layers mixed together for 1-hour, followed by sonicating for 30 minutes. The obtained mixture is layered in Petri dish with area $63.64 \mathrm{~cm}^{2}$ and dried at 50 to $55^{\circ} \mathrm{C}$ for 24 hours, and the obtained films peeled-off and cut to $2 \times 2 \mathrm{~cm}^{2}$ size.

\section{Response Surface Method (RSM)}

The CCD employed for optimizing main effects, interaction effects, and quadratic effects of the process variables on the tensile strength, disintegration time, and cumulative $\%$ drug released. The design comprises of center points and midpoints at each edge of multidimensional cube. These designs are rotatable (or near rotatable), and require three levels of each factor. ${ }^{[6]}$

The method explains the effect of one factor on another. In current research, the effect of glycerol is demonstrated on HPMC E50, maltodextrin. About 27 mouth dissolving films (CF1-CF27) were prepared, employing $3^{3}$ RSM, in which $3^{3}$ demonstrates three variables at three different levels of HPMC E50, maltodextrin, and glycerol employing DoE software.

Table 1: Formulation of mouth dissolving oral films containing citalopram $\mathrm{HBr}$

\begin{tabular}{|c|c|c|c|c|c|c|c|c|}
\hline F. No. & $\begin{array}{l}\text { Citalopram } \mathrm{HBr} \\
(\mathrm{mg})\end{array}$ & $\begin{array}{l}\text { HPMC E50 } \\
(\mathrm{mg})\end{array}$ & Maltodextrin $(\mathrm{mg})$ & $\begin{array}{l}\text { Glycerol } \\
(\mathrm{mg})\end{array}$ & $\begin{array}{l}\text { Lactose } \\
(\mathrm{mg})\end{array}$ & Aspartame (mg) & $\begin{array}{l}\text { Flavor } \\
(\mathrm{mL})\end{array}$ & $\begin{array}{l}\text { Water } \\
(\mathrm{mL})\end{array}$ \\
\hline CF1 & 20 & 45 & 25 & 10 & 10 & 4 & 0.1 & 10 \\
\hline CF2 & 20 & 45 & 20 & 10 & 10 & 4 & 0.1 & 10 \\
\hline CF3 & 20 & 45 & 30 & 15 & 10 & 4 & 0.1 & 10 \\
\hline CF4 & 20 & 45 & 30 & 10 & 10 & 4 & 0.1 & 10 \\
\hline CF5 & 20 & 45 & 20 & 20 & 10 & 4 & 0.1 & 10 \\
\hline CF6 & 20 & 45 & 25 & 10 & 10 & 4 & 0.1 & 10 \\
\hline CF7 & 20 & 35 & 30 & 20 & 10 & 4 & 0.1 & 10 \\
\hline CF8 & 20 & 45 & 30 & 20 & 10 & 4 & 0.1 & 10 \\
\hline CF9 & 20 & 35 & 25 & 15 & 10 & 4 & 0.1 & 10 \\
\hline CF10 & 20 & 45 & 25 & 15 & 10 & 4 & 0.1 & 10 \\
\hline CF11 & 20 & 40 & 20 & 15 & 10 & 4 & 0.1 & 10 \\
\hline CF12 & 20 & 40 & 30 & 15 & 10 & 4 & 0.1 & 10 \\
\hline CF13 & 20 & 40 & 25 & 10 & 10 & 4 & 0.1 & 10 \\
\hline CF14 & 20 & 40 & 25 & 20 & 10 & 4 & 0.1 & 10 \\
\hline CF15 & 20 & 40 & 25 & 15 & 10 & 4 & 0.1 & 10 \\
\hline CF16 & 20 & 40 & 30 & 20 & 10 & 4 & 0.1 & 10 \\
\hline CF17 & 20 & 35 & 30 & 10 & 10 & 4 & 0.1 & 10 \\
\hline CF18 & 20 & 40 & 25 & 20 & 10 & 4 & 0.1 & 10 \\
\hline CF19 & 20 & 35 & 20 & 15 & 10 & 4 & 0.1 & 10 \\
\hline CF20 & 20 & 35 & 25 & 10 & 10 & 4 & 0.1 & 10 \\
\hline CF21 & 20 & 40 & 30 & 10 & 10 & 4 & 0.1 & 10 \\
\hline CF22 & 20 & 35 & 30 & 15 & 10 & 4 & 0.1 & 10 \\
\hline CF23 & 20 & 35 & 25 & 20 & 10 & 4 & 0.1 & 10 \\
\hline CF24 & 20 & 35 & 20 & 10 & 10 & 4 & 0.1 & 10 \\
\hline CF25 & 20 & 35 & 20 & 20 & 10 & 4 & 0.1 & 10 \\
\hline CF26 & 20 & 35 & 30 & 20 & 10 & 4 & 0.1 & 10 \\
\hline CF27 & 20 & 40 & 20 & 20 & 10 & 4 & 0.1 & 10 \\
\hline
\end{tabular}


Study type: response surface

Design type: central composite

Design mode: quadratic

\section{Statistical Analysis}

Data were analyzed using Stat-Ease Design-Expert ${ }^{\circledR}$ software v8.0.1 to obtain analysis of variance (ANOVA), regression coefficients, and regression equation. Mathematical relationships were generated by multiple linear regression analysis for the mentioned variables that demonstrate the effects of amount of HPMC E50 (A), amount of maltodextrin (B), and amount of glycerol (C), and their interaction on tensile strength (Y1), disintegration time (Y2,) and cumulative \% drug release after 10 minutes (Y3). The values of $\mathrm{A}, \mathrm{B}$, and $\mathrm{C}$ are related to their effects on responses $\mathrm{Y} 1, \mathrm{Y} 2$, and $\mathrm{Y} 3$. The statistical significance ( $p>0.05)$, determined using ANOVA, as per the provisions of Design-Expert software. ${ }^{[7]}$

\section{Evaluation of Citalopram HBr Mouth Dissolving Film}

Thickness Uniformity

Vernier caliper instrument [Mitutoyo (absolute digimatic), Mumbai] with $0.01 \mathrm{~mm}$ least count is used to measure the thickness of films. ${ }^{[8]}$

\section{Weight Uniformity}

Randomly chosen films are weighed individually on analytical balance (Shimadzu, Japan) to obtain average weight. ${ }^{[8]}$

\section{Drug Content Uniformity}

The films are dissolved in phosphate buffer ( $\mathrm{pH} 4)$ and stirred for an hour. The amount of drug dissolved is analyzed at $227 \mathrm{~nm}$ using a UV spectrophotometer (Shimadzu, Japan). The measurement carried out in quintuplicate to find the standard deviation. ${ }^{[9]}$

\section{Folding Endurance (FE)}

The formulated films are repeatedly folded at one particular place until it breaks. The number of folds required to break the film is noted as folding endurance. ${ }^{[10]}$

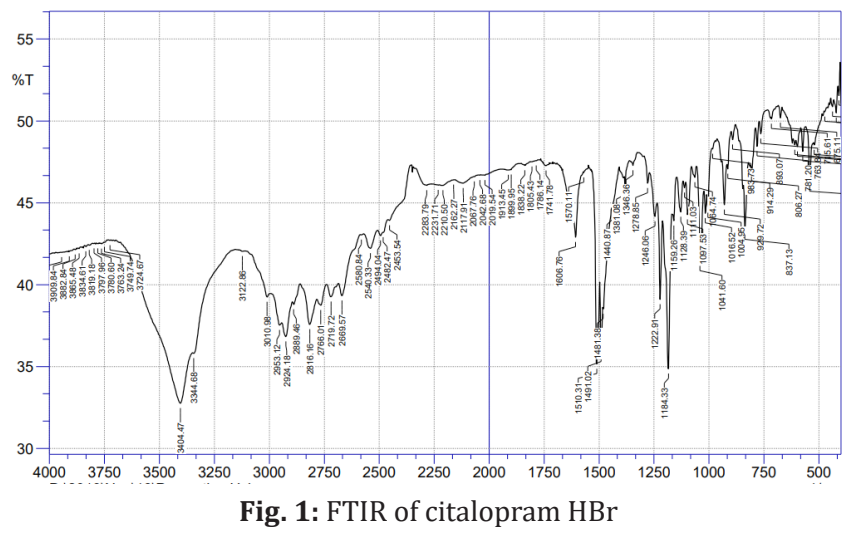

Surface $p H$

The film dissolved in $2 \mathrm{~mL}$ of phosphate buffer ( $\mathrm{pH}$ 6.8). The $\mathrm{pH}$ of resultant solution determined by $\mathrm{pH}$ meter (Electro lab, Mumbai). ${ }^{[11]}$

\section{Tensile Strength (TS)}

The films were held between two clamps placed $3 \mathrm{~cm}$ apart. A clipboard attached using tape to prevent cut down of the film by grooves. Weights added in the pan that pulls the strips apart till they break. The force required to break the strip is calculated by dividing load applied with strip area of cross-section. ${ }^{[12]}$

\section{Disintegration Time (DT)}

The film placed on Petri dish that contains about $10 \mathrm{~mL}$ phosphate buffer ( $\mathrm{pH}$ 6.8).The time taken for the strip to break is considered as disintegration time. ${ }^{[13,14]}$

\section{Cumulative Percentage Drug Release (CDR)}

The drug release of citalopram $\mathrm{HBr}$ mouth dissolving films is analyzed in saliva fluids of $\mathrm{pH} 6.8$ used as dissolution medium followed by stirring at $37 \pm 5^{\circ} \mathrm{C}$ at $100 \mathrm{rpm}$ speed. The samples were withdrawn at various intervals and analyzed by spectrophotometrically at $227 \mathrm{~nm}^{[15,16]}$

\section{Fourier Transform Infrared (FTIR) Spectroscopy}

FTIR spectrophotometer (Schimadzu FTIR 8400S, Japan) was used to record the FTIR spectra of pure drug and formulated films in 4,000 to $400 \mathrm{~cm}^{-1}$ range. ${ }^{[17]}$

\section{RESULTS}

\section{Drug Authentication Study}

The presence of broad band at 3,404 to $3,341 \mathrm{~cm}^{-1}$ for $\mathrm{C}-\mathrm{H}$ aromatic stretching, 2,953 to $2,924 \mathrm{~cm}^{-1}$ for aliphatic $\mathrm{C}-\mathrm{H}$ stretching, 2,283 $\mathrm{cm}^{-1}$ for $\mathrm{CN}$ stretching, $1,491 \mathrm{~cm}^{-1}$ for $\mathrm{CH}_{2}$ bending and $1,184 \mathrm{~cm}^{-1}$ for $\mathrm{C}-\mathrm{F}$ stretching confirms the purity of citalopram $\mathrm{HBr}$ (Fig. 1).

\section{Preparation of Citalopram HBr Mouth Dissolving Films}

Twenty-seven mouth dissolving films of citalopram $\mathrm{HBr}$ prepared using $25 \mathrm{mg}$ per $4 \mathrm{~cm}^{2}$ film employing different polymers in varying concentrations, as represented in Table 1.

\section{Cumulative Percentage Drug Release (CDR)}

The drug release of all 27 citalopram $\mathrm{HBr}$ mouth dissolving film formulations varied among $72.15 \pm 1.8 \%$ to $98.41 \pm 1.81 \%$. Maximum drug release exhibited for CF21 $(98.41 \pm 1.81 \%)$ within 10 minutes, that is, higher than that of pure drug $86.78 \pm 1.53 \%$ (Figs 2 to 5 ).

\section{Physico-Chemical Evaluation of Citalopram $\mathrm{HBr}$ Mouth Dissolving Films}

The mouth dissolving film thickness arises due to variations in polymer viscosity. The thickness of CF1 to 


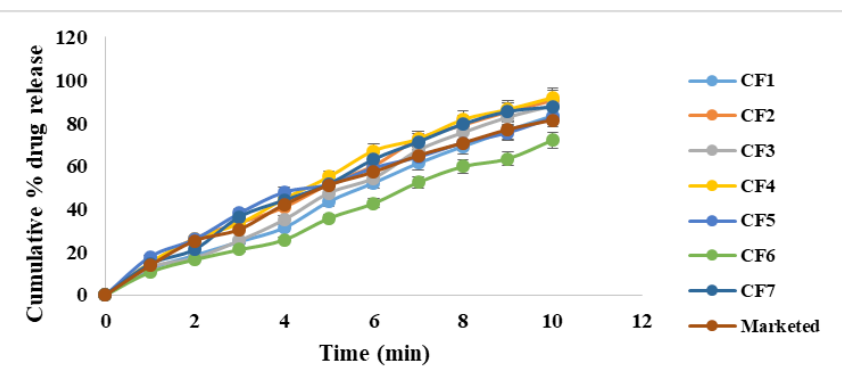

Fig. 2: In vitro CDR profile of formulations CF1-CF7 and marketed formulation

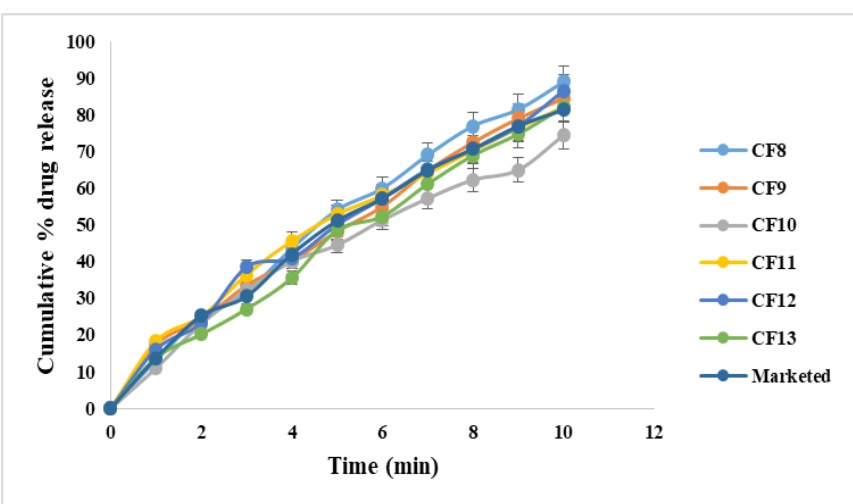

Fig. 3: In vitro CDR profile of formulations CF8-CF13 and marketed formulation

CF27 is within $0.12 \pm 0.58$ to $0.34 \pm 0.56 \mathrm{~mm}$. The tensile strength of all formulation CF1 to CF27 ranged between $19.53 \pm 1.37$ to $67.2 \pm 1.31$ grams (Table 2 ).

The folding endurance is the measure of the ability of film to withstand rupture. The formulations containing higher amounts of polymer exhibited excellent folding endurance of 297. Folding endurance of 27 formulations ranged between $242 \pm 1.62$ to $297 \pm 1.89$ with maximum value exhibited by CF21.

The drug content uniformity (\%) of CF1 to CF27 ranged within $95.14 \pm 1.37$ to $99.83 \pm 1.87 \%$, indicating maximum drug distribution uniformity throughout the film with maximum uniformity observed in CF21. The surface $\mathrm{pH}$ of mouth dissolving films determines the occurrence of any side effects and mucous irritation. The $\mathrm{pH}$ of all films ranged between $6.30 \pm 0.92$ to $6.77 \pm 0.22$ indicating no irritation in mucosal lining (Table 2).

The disintegration time (seconds) of all films CF1 to CF27 was found to be in the range of $9 \pm 1.6$ to $19 \pm 1.4$ seconds. The formulations with higher drug concentration exhibited larger disintegration time. The formulation CF21 exhibited a minimum value of 9 seconds (Table 2).

\section{Design of Experiment and Statistical Analysis}

Based on CCD, the effect of glycerol (C) on HPMC E50 (A), amount of maltodextrin (B) is explained, and evaluated the main effects, interaction effects, and quadratic effects of the process variables on the tensile strength, disintegration time, and cumulative $\%$ drug released.

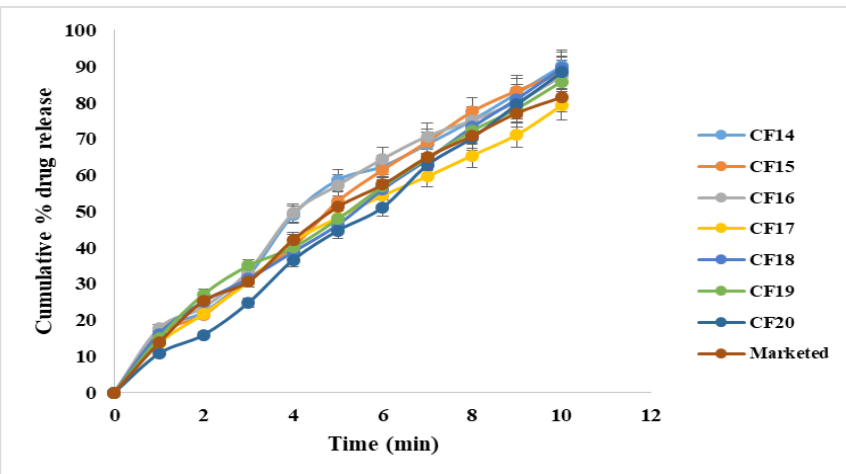

Fig. 4: In vitro CDR profile of formulations CF14-CF20 and marketed formulation

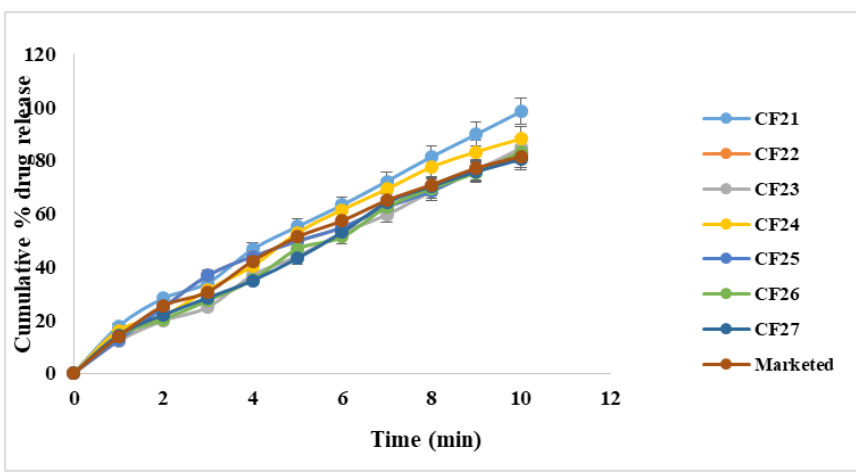

Fig. 5: In vitro CDR profile of formulations CF21-CF27 and marketed formulation

All responses substituted into second quadratic equation and the adequacy of the model verified by ANOVA, using Design-Expert software. For all the three responses, the quadratic model generated the highest $F$ value, hence, considered as fitting model. All of the responses exhibited a significant lack-of-fit $F$ value ( $p>0.05$ ), further supporting the adequacy of the model fit. The R2 value signifies the measure of the amount of variation around the mean (Table 3).

\section{Tensile Strength (Y1)}

The tensile strength of all films ranged between 19.5 and 67.2 grams (Table 2). The quadratic model generated unveiled that amount of HPMC E50 (A) amount maltodextrin (B), and amount of glycerol have a significant influence on the tensile strength. The predicted and observed values are in close agreement, as seen in Table 4. Results of the equation indicate that the effect of $B$ is more significant than $\mathrm{A}$ and $\mathrm{C}$. The factorial equation for droplet size showed a good correlation coefficient (0.9993). The mathematical model generated for $Y 1$ with an $F$ value of 0 , implying that the model is significant. There exists a $0.02 \%$ chance that a "model $\mathrm{F}$ value" due to noise. The independent variables $A, B, C$, and the quadratic term of $A B, B C, A^{2}$, and $B^{2}$ have significant effects on the tensile strength, since the $\mathrm{p}$ values, less than 0.05 represent the significant model (Table 3). The "lack of fit F value" of 0.0312 indicates lack of fit is significant relative to the pure error. There is a $1.58 \%$ chance that a "lack of fit F value" this large 
Application of Citalopram Hydrogen Bromide Mouth Dissolving Films

Table 2: Physicochemical evaluation of mouth dissolving films of citalopram HBr (CF1-CF27)

\begin{tabular}{|c|c|c|c|c|c|c|}
\hline F. No. & Thickness (mm) & Tensile strength (gm) & Folding endurance & Content uniformity (\%) & Surface $p H$ & $D T(\mathrm{sec})$ \\
\hline CF1 & $0.33 \pm 0.62$ & $43.47 \pm 1.22$ & $242 \pm 1.62$ & $98.02 \pm 1.37$ & $6.34 \pm 0.65$ & $12 \pm 1.23$ \\
\hline CF2 & $0.27 \pm 0.48$ & $35.12 \pm 1.68$ & $288 \pm 1.65$ & $96.53 \pm 1.84$ & $6.41 \pm 0.26$ & $14 \pm 1.51$ \\
\hline CF3 & $0.23 \pm 0.89$ & $47.39 \pm 1.27$ & $249 \pm 1.78$ & $97.13 \pm 1.69$ & $6.53 \pm 0.98$ & $19 \pm 1.4$ \\
\hline CF4 & $0.28 \pm 0.02$ & $43.85 \pm 1.89$ & $271 \pm 1.12$ & $97.48 \pm 1.27$ & $6.48 \pm 0.23$ & $16 \pm 1.19$ \\
\hline CF5 & $0.31 \pm 0.33$ & $58.44 \pm 1.16$ & $283 \pm 1.81$ & $96.58 \pm 1.13$ & $6.52 \pm 0.78$ & $15 \pm 1.25$ \\
\hline CF6 & $0.24 \pm 0.42$ & $61.76 \pm 1.37$ & $268 \pm 1.28$ & $97.37 \pm 0.96$ & $6.49 \pm 0.37$ & $12 \pm 1.87$ \\
\hline CF7 & $0.19 \pm 0.58$ & $48.79 \pm 1.43$ & $274 \pm 1.37$ & $96.82 \pm 1.98$ & $6.6 \pm 0.15$ & $15 \pm 1.63$ \\
\hline CF8 & $0.27 \pm 0.83$ & $62.47 \pm 1.78$ & $264 \pm 1.48$ & $95.14 \pm 1.37$ & $6.47 \pm 0.13$ & $18 \pm 1.37$ \\
\hline CF9 & $0.15 \pm 0.93$ & $19.53 \pm 1.37$ & $261 \pm 1.82$ & $96.84 \pm 1.69$ & $6.34 \pm 0.56$ & $13 \pm 1.19$ \\
\hline CF10 & $0.30 \pm 0.27$ & $55.24 \pm 1.61$ & $290 \pm 1.64$ & $96.19 \pm 1.73$ & $6.38 \pm 0.97$ & $16 \pm 1.45$ \\
\hline CF11 & $0.26 \pm 0.95$ & $32.12 \pm 1.56$ & $277 \pm 1.21$ & $97.38 \pm 1.61$ & $6.53 \pm 0.19$ & $14 \pm 1.19$ \\
\hline CF12 & $0.23 \pm 0.03$ & $65.80 \pm 1.44$ & $262 \pm 1.47$ & $96.17 \pm 1.28$ & $6.29 \pm 0.78$ & $15 \pm 1.4$ \\
\hline CF13 & $0.27 \pm 0.32$ & $39.49 \pm 1.92$ & $273 \pm 1.25$ & $97.50 \pm 1.63$ & $6.37 \pm 0.29$ & $13 \pm 1.17$ \\
\hline CF14 & $0.34 \pm 0.56$ & $53.41 \pm 1.88$ & $264 \pm 1.86$ & $96.17 \pm 1.45$ & $6.53 \pm 0.38$ & $16 \pm 1.87$ \\
\hline CF15 & $0.16 \pm 0.17$ & $36.36 \pm 1.43$ & $276 \pm 1.16$ & $97.23 \pm 1.41$ & $6.37 \pm 0.15$ & $11 \pm 1.47$ \\
\hline CF16 & $0.28 \pm 0.37$ & $47.18 \pm 1.28$ & $265 \pm 1.37$ & $97.35 \pm 1.60$ & $6.39 \pm 0.38$ & $17 \pm 1.81$ \\
\hline CF17 & $0.19 \pm 0.17$ & $43.73 \pm 1.55$ & $269 \pm 1.21$ & $98.53 \pm 1.78$ & $6.54 \pm 0.69$ & $14 \pm 1.56$ \\
\hline CF18 & $0.22 \pm 0.85$ & $58.20 \pm 1.48$ & $260 \pm 1.37$ & $96.16 \pm 1.97$ & $6.48 \pm 0.34$ & $15 \pm 1.12$ \\
\hline CF19 & $0.25 \pm 0.37$ & $48.63 \pm 1.21$ & $289 \pm 1.1$ & $98.28 \pm 1.84$ & $6.55 \pm 0.67$ & $13 \pm 1.33$ \\
\hline CF20 & $0.21 \pm 0.63$ & $56.28 \pm 1.44$ & $263 \pm 1.47$ & $97.14 \pm 1.65$ & $6.47 \pm 0.15$ & $12 \pm 132$ \\
\hline CF21 & $0.12 \pm 0.58$ & $67.21 \pm 1.31$ & $297 \pm 1.89$ & $99.83 \pm 1.87$ & $6.77 \pm 0.22$ & $9 \pm 1.6$ \\
\hline CF22 & $0.28 \pm 0.44$ & $24.67 \pm 1.87$ & $260 \pm 1.38$ & $97.62 \pm 1.73$ & $6.19 \pm 0.21$ & $11 \pm 1.61$ \\
\hline CF23 & $0.23 \pm 0.81$ & $51.52 \pm 1.47$ & $262 \pm 1.38$ & $98.19 \pm 1.64$ & $6.35 \pm 0.97$ & $12 \pm 1.49$ \\
\hline CF24 & $0.27 \pm 0.43$ & $21.9 \pm 1.33$ & $273 \pm 1.29$ & $97.38 \pm 1.16$ & $6.39 \pm 0.20$ & $18 \pm 1.31$ \\
\hline CF25 & $0.32 \pm 0.11$ & $49.25 \pm 1.47$ & $268 \pm 1.23$ & $98.76 \pm 1.28$ & $6.58 \pm 0.38$ & $13 \pm 1.39$ \\
\hline CF26 & $0.27 \pm 0.44$ & $50.57 \pm 1.07$ & $280 \pm 1.69$ & $96.39 \pm 1.17$ & $6.3 \pm 0.92$ & $16 \pm 1.4$ \\
\hline CF27 & $0.26 \pm 0.78$ & $37.43 \pm 1.11$ & $263 \pm 1.14$ & $97.67 \pm 1.26$ & $6.45 \pm 0.67$ & $15 \pm 1.77$ \\
\hline
\end{tabular}

Values are expressed in mean \pm SD; $(n=3)$

Table 3: Regression equations of the fitted models

\begin{tabular}{ll}
\hline Response & Equation \\
\hline Tensile strength (Y1) & $17.15+12.84 \mathrm{X} 1-7.21 \mathrm{X} 2-3.36 \mathrm{X} 3-1.41 \mathrm{X}_{1}{ }^{2}+2.98 \mathrm{X}_{1} \mathrm{X}_{3}+11.13 \mathrm{X}_{2}{ }^{2}-2.34 \mathrm{X}_{2} \mathrm{X}_{3}+1.55 \mathrm{X}_{3}{ }^{2}$ \\
Disintegration time (Y2) & $25+12 \mathrm{X} 1+10 \mathrm{X} 2+7 \mathrm{X} 3+8 \mathrm{X}_{1}^{2}-9 \mathrm{X}_{1} \mathrm{X}_{3}-15 \mathrm{X}_{2}{ }_{2}-4 \mathrm{X}_{2} \mathrm{X}_{3}-5 \mathrm{X}^{2}{ }_{3}$ \\
$\%$ cumulative drug released (Y3) & $73.47-5.61 \mathrm{X} 1+18.35 \mathrm{X} 2-15.17 \mathrm{X} 3+1.75 \mathrm{X}_{1}{ }^{2}-11.10 \mathrm{X}_{1} \mathrm{X}_{3}+5.75 \mathrm{X}_{2}{ }^{2}-27.15 \mathrm{X}_{2} \mathrm{X}_{3}+4.31 \mathrm{X}_{3}{ }^{2}$ \\
\hline
\end{tabular}

Table 4: Optimized values obtained by the constraints applies on Y1, Y2, and Y3

\begin{tabular}{|c|c|c|c|c|c|c|c|c|}
\hline \multirow[b]{2}{*}{ Independent variable } & \multirow{2}{*}{$\begin{array}{l}\text { Nominal } \\
\text { value } \%\end{array}$} & \multicolumn{3}{|c|}{ Predicted values } & \multicolumn{4}{|c|}{ Observed values } \\
\hline & & $T S(n m)(Y 1)$ & $D T(\mathrm{Sec})(\mathrm{Y} 2)$ & $\% C D R(Y 3)$ & Batch & $T S(n m)(Y 1)$ & $D T(Y 2)$ & $\% C D R(Y 3)$ \\
\hline Amount of HPMC E50 (A) & 40 & & & & 1 & 67.4 & 9 & 97.23 \\
\hline Amount of maltodextrin (B) & 30 & 67.2 & 9 & 98.41 & 2 & 67.1 & 12 & 98.78 \\
\hline Amount of glycerol (C) & 10 & & & & 3 & 67.5 & 15 & 97.5 \\
\hline
\end{tabular}

Values are expressed in mean $\pm S D ;(n=3)$

could occur due to noise. The influence of the main and interactive effects of factors on the tensile strength was further elucidated using the contour and 3D response surface plots. The relationship between the dependent and independent variables was further elucidated using a 3D response surface and corresponding contour plots. The 
interaction between $\mathrm{B}$ and $\mathrm{C}$ on $\mathrm{Y} 1$ at a fixed level of $\mathrm{A}$, is shown in Fig. 6. The respective contour plots are shown in Fig. 7.

There exists a negligible effect on Y1 of formulations as polymers used posses superior tensile strength, and there exists minimum influence on tensile strength by glycerol.

\section{Disintegration Time (Y2)}

The disintegration time (Y2) of all formulations ranged between 9 and 19 seconds (Table 2). The quadratic models generated revealed that the amount of maltodextrin and the amount of glycerol has a significant influence on the disintegration time (Table 3 ). Results of the equation indicate that the effect of $\mathrm{B}$ is more significant than $\mathrm{A}$ and $\mathrm{C}$. The factorial equation for disintegration time showed a good correlation coefficient (0.9998). The theoretical (predicted) values and the observed values were in reasonably good agreement, as seen. The mathematical model generated for Y2 was found to be significant, with $\mathrm{F}$ value of 0.0275 implies the model is significant.

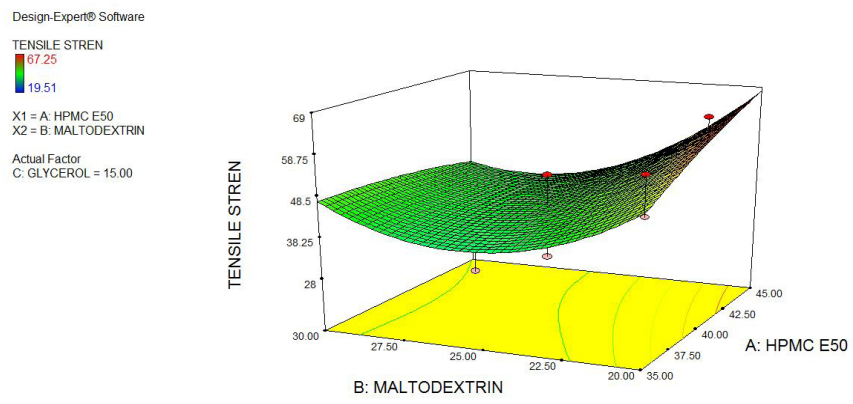

Fig. 6: Response 3D surface plot demonstrating the influence of amount of HPMC E50 and amount of maltodextrin on tensile strength fixed level of $\mathrm{C}$

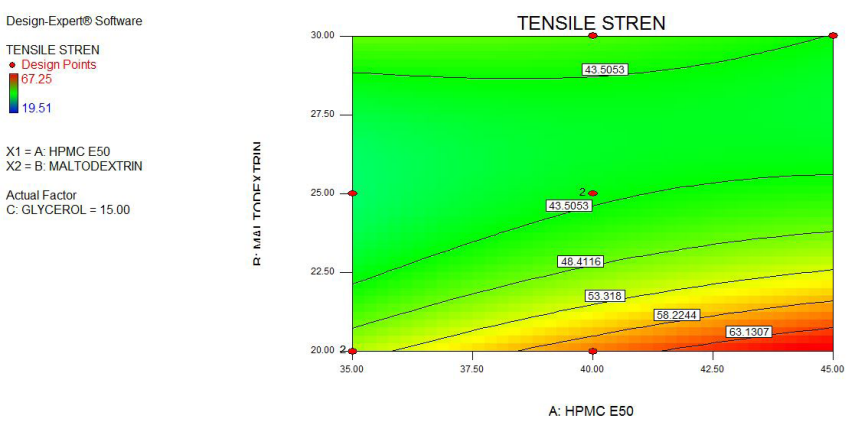

Fig. 7: Contour plot showing the influence of amount of HPMC E50 and amount of maltodextrin on tensile strength fixed level of $\mathrm{C}$
There is only a $1 \%$ chance that a "model F value" this large could occur due to noise. Values of "prob > F" less than 0.05 indicate model terms are significant. In this case, B and C are significant model terms. The "lack of fit F value" of 0.0469 implies the lack of fit is significant relative to the pure error. There is a $2.71 \%$ chance that a "lack of fit F value" this large could occur due to noise. A significant lack of fit is good 0.0469; we want the model to fit. The relationship between the dependent and independent variables was further elucidated using 3D response surface plots and corresponding contour plots. The interaction between $\mathrm{A}$ and $\mathrm{B}$ on Y2 at a fixed level of $\mathrm{C}$, is shown in Fig. 8. The respective contour plots are as shown in Fig. 9. The plots indicate that as amount of polymer increases, the Y2 decreases, and as the amount of plasticizer increases, Y2 also increases.

\section{Cumulative Percent Drug Released (Y3)}

The cumulative percent drug release in 10 minutes from the mouth dissolving films was found to be in the range of 74.62 to $98.41 \%$. The quadratic model generated revealed
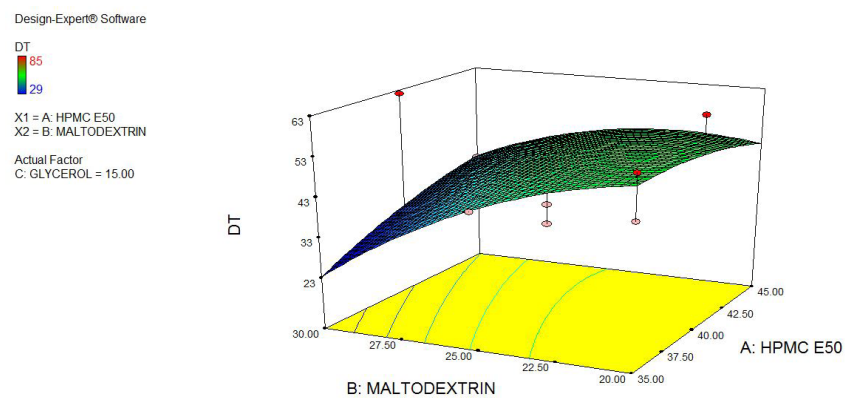

Fig. 8: Response 3D surface plot showing the influence of amount of HPMC E50 and amount of maltodextrin on disintegration time fixed level of $\mathrm{C}$
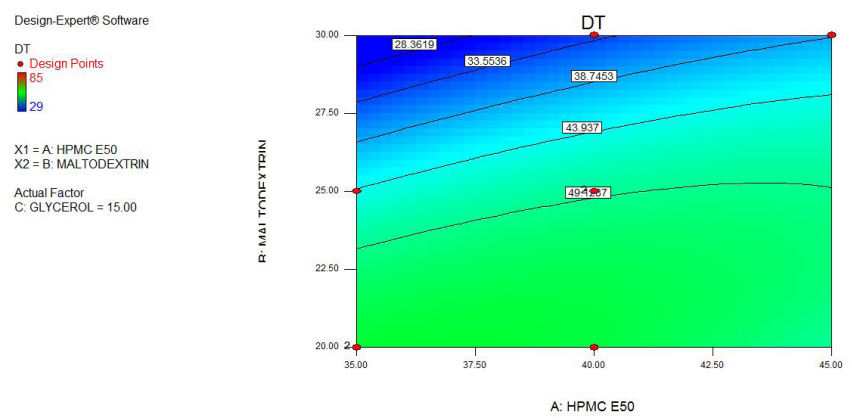

Fig. 9: Contour plot showing the influence of amount of HPMC E50 and amount of maltodextrin on disintegration time fixed level of $\mathrm{C}$

Table 5: Accelerated stability study of formulation CF21

\begin{tabular}{|c|c|c|c|c|}
\hline \multirow[b]{3}{*}{ Parameters } & \multicolumn{4}{|c|}{ Temperature maintained at $40 \pm 2^{\circ} \mathrm{C}$} \\
\hline & \multicolumn{4}{|c|}{ Relative humidity ( $R H$ ) maintained at $75 \pm 5 \%$} \\
\hline & Initial & After 1 month & After 2 months & After 3 months \\
\hline Tensile strength (\%) & $67.21 \pm 1.37$ & $67.18 \pm 1.53$ & $67.14 \pm 1.42$ & $67.12 \pm 1.35$ \\
\hline CDR $(\%)$ & $98.41 \pm 1.87$ & $98.35 \pm 1.48$ & $98.28 \pm 1.15$ & $98.17 \pm 1.10$ \\
\hline Disintegration time (sec) & $9 \pm 1.22$ & $9 \pm 1.41$ & $9 \pm 1.63$ & $9 \pm 1.89$ \\
\hline
\end{tabular}

Values are expressed in mean $\pm S D ;(n=3)$ 


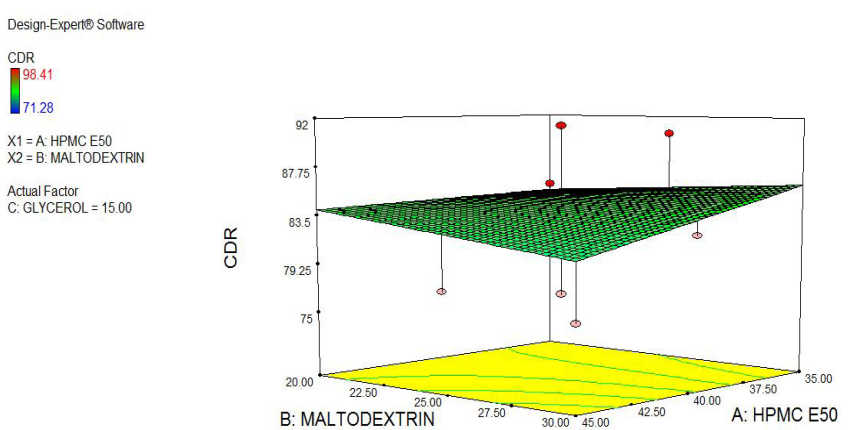

Fig. 10: Response 3D surface plot showing the influence of amount of HPMC E50 and amount of maltodextrin on cumulative percent drug released fixed level of $\mathrm{C}$
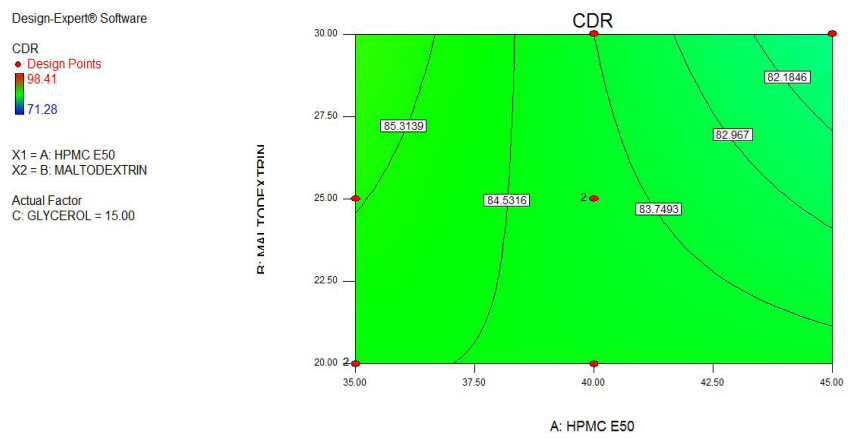

Fig. 11: Contour plot showing the influence of amount of HPMC E50 and amount of maltodextrin on cumulative percent drug released fixed level of C

that the amount of HPMC E50, amount of maltodextrin, and amount of glycerol have a significant influence on the cumulative percent drug (Table 3). Results of the equation indicate that the effect of $B$ is more significant than $\mathrm{A}$ and $\mathrm{C}$. The factorial equation for percent drug release showed a good correlation coefficient (0.9996). The theoretical (predicted) values and the observed values were in reasonably good agreement, as seen (Table 4). The mathematical model generated for percent drug release in 10 minutes (Y3) was found to be significant with $\mathrm{F}$ value of 0.0265 implies the model is significant. There is only a $0.17 \%$ chance that a "model F value" this large could occur due to noise. Values of "prob $>$ F" less than 0.05 indicate model terms are significant. Values $>0.05$ indicate the model terms are not significant. The "lack of fit F value" of 0.0192 implies the lack of fit is significant relative to the pure error. There is a $2.13 \%$ chance that a "lack of fit $\mathrm{F}$ value" this large could occur due to noise. The interaction between $A$ and $B$ on percent drug release at a fixed level of $\mathrm{C}$ is shown in Fig. 10. The respective contour plots are as shown in Fig. 11. The plots indicate that increase in Y3 depends on the instant dispersion of drug post-dissolution of the film in the saliva. This value is further improved on adding penetration enhancers. The graphs indicate that glycerol has a significant effect on Y3. As the amount of polymer increases, the Y3 decreases, and as the amount of plasticizer increases, the $\mathrm{Y} 3$ also increases.

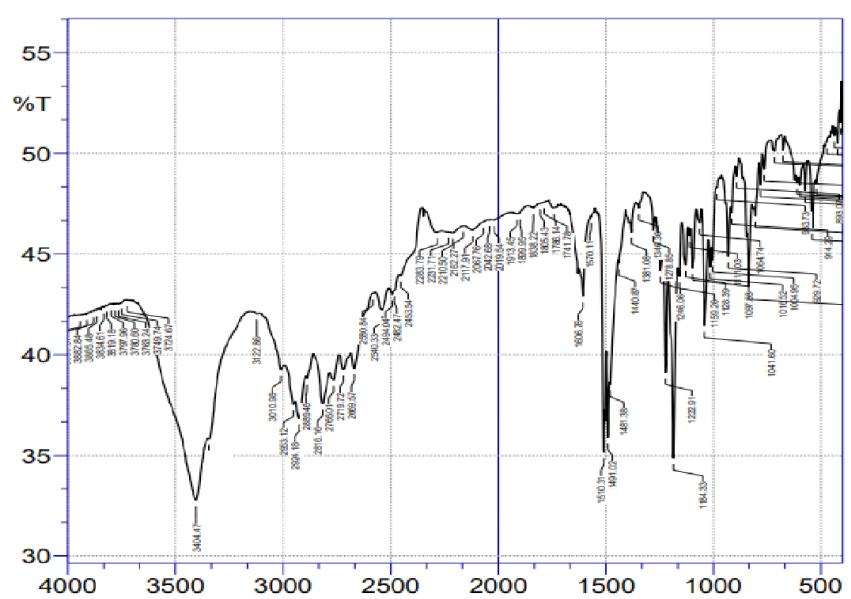

Fig. 12: FTIR of optimized citalopram $\mathrm{HBr}$ mouth dissolving film (CF21)

\section{Optimization by Desirability Function}

The responses: tensile strength (Y1), disintegration time (Y2), and cumulative percentage $\%$ drug released in 10 minutes (Y3) were transformed into the desirability scale. Among them, Y1 and Y2 are minimized, while Y3 is maximized. In individual desirability function, $Y_{\max }$ and $Y_{\min }$ are considered highest and objective function (D) calculated for each response, which is combined to obtain global desirability value using Design-Expert software.

The maximum function values generated at X1:40, $\mathrm{X} 2: 30$, and X3:10.Three batches of films formulated with optimized ratios obtained and evaluated. There existed descent agreement amongst predicted and observed values (Table 4), and hence, the results validated.

\section{Characterization of Optimized Citalopram $\mathrm{HBr}$ Mouth Dissolving Film (CF21)}

\section{FTIR Analysis}

The FTIR spectra of optimized formulation CF21 (Fig. 12) exhibited all characteristic peaks of pure drug present in Fig. 1, indicating the absence of interaction between the drug, polymers, and plasticizer used.

\section{Stability Studies}

The formulation CF21 subjected to accelerated stability study for 3 months adhering to ICH guidelines. The results indicate no significant alteration in appearance and flexibility. No significant variation in tensile strength, in vitro drug release, and disintegration time observed confirming the stability of polymer (Table 5 ).

\section{DISCUSSION}

In the present work, mouth-dissolving films of citalopram $\mathrm{HBr}$ were prepared and optimized using CCD. Total 27 formulations (CF1-CF27) prepared using direct compression method and optimized by $3^{3}$ RSM using HPMC E50, maltodextrin, and glycerol by experiment software. 
All the formulation evaluated for physicochemical parameters and drug release studies. The formulation CF21 with maximum tensile strength of $67.21 \pm 1.31$ grams, least disintegration time of $9 \pm 1.6$ seconds, and highest drug release of $98.41 \pm 1.81 \%$ was chosen as optimized formulation with maximum content uniformity and folding endurance. From the above results, we can conclude that the developed formulation can be an innovative dosage form to improve the drug delivery, quick onset of action, as well as, improve patient compliance in the management of depression.

\section{REFERENCES}

1. Seager HJ. Drug delivery products and zydis fast dissolving dosage forms. Pharm Pharmcol. 1998;50:375-382.

2. Gohel M, Patel M, Amin A, Agrawal R, Dave R, Bariya N. Formulation design and optimization of mouth dissolve Tablets of nimesulide using vacuum drying technique. AAPS Pharm Sci Tech. 2004;5:36.

3. Carandang C, Jabbal R, Macbride A, Elbe D. A review of escitalopram and citalopram in child and adolescent depression. J Can Acad Child Adolesc Psychiatry. 2011;20(4):315-324.

4. Schwartz BJ, Connor RE. Optimization technique in pharmaceutical formulations and processing. J Drugs Pharm Sci Modern Pharm. 1996;72:727-754.

5. Keshavarao KP, Dixit M. Formulation and evaluation of mouth dissolving film containing rofecoxib. IRJP. 2011;2(3):273-278.

6. Montgomery, Douglas C. Design and Analysis of Experiments: Response surface method and designs, John Wiley and Sons, Inc. New Jersey; 2005. p. 210-256.

7. Nair R, Sevukarajan M, Vishnu PK, Arun KK. Response surface methodology for the optimization of ethyl cellulose microspheres Int J of Pharm Tech Res. 2014;3(2):775-783.

8. Cilurzo F, Cupone IE, Minghetti P, Selmin, Montanari L. Fast dissolving films made of maltodextrins. Eur J Pharm Biopharm. 2008;70(3):895-900.

9. Kulkarni AS, Deokule HA, Mane MS, Ghadge DM. Exploration of different polymers for use in the formulation of oral fast dissolving strips. J Current Pharm Res. 2010;2(1):33-35.

10. Corniello C. Quick dissolving strips: from concept to commercialization. Drug Del Technol. 2006;6(2):68-71.

11. Londhe VY, Umalkar KB. Formulation development and evaluation of fast dissolving film of telmisartan. Ind J Pharm Sci. 2012;74(2): 122-126.

12. Maheswari KM, Devineni PK, Deekonda S, Shaik S, Uppala NP, Nalluri BN. Development and evaluation of mouth dissolving films of amlodipine besylate for enhanced therapeutic efficacy. J of Pharmaceu. 2014:1-10.

13. Bala R, Pawar P, Khanna S, Arora S. Orally dissolving strips: A new approach to oral drug delivery system. Int J Pharm Investig. 2013;3(2):67-76.

14. Panchal MS, Patel H, Bagada A, Vadalia KR. Formulation and evaluation of mouth dissolving film of ropinirole hydrochloride by using pullulan polymers. Int J Pharm Res and Alli Sci. 2012;1(3): 60-72.

15. Pankaj K, Ashok LG, Bharat BS, Shubhanjali S. Design and comparative evaluation of in vitro drug release, pharmacokinetics and gamma scintigraphic analysis of controlled release Tablets using novel $\mathrm{pH}$ sensitive starch and modified starch-acrylate graft copolymer matrices. Iran J Pharm Res. 2015;14(3):677-691.

16. Bala $R$, Khanna S, Pawar P. Design optimization and in vitro-in vivo evaluation of orally dissolving strips of clobazam. J Drug Deliv. 2014;3:92783.

17. Senthilkumar K, Vijaya C. Formulation development of mouth dissolving film of etoricoxib for pain management. Adv in Pharmaceu. 2015:1-11.

HOW TO CITE THIS ARTICLE: Reddy SR, Ramesh B. Application of central composite design for citalopram hydrogen bromide mouth dissolving films. Int. J. Pharm. Sci. Drug Res. 2020;12(4):360-367. DOI: 10.25004/IJPSDR.2020.120408 